\title{
The surprising benefit of passive- aggressive behaviour at Christmas parties: being crowned king of the crackers
}

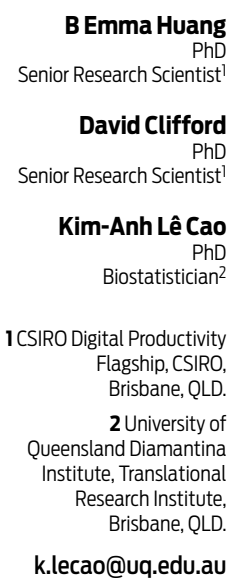

MJA 2014; 201: 694-696 doi: 10.5694/mjal4.01392

Crack!

How does Jack Frost get to work?

By icicle.

$\mathrm{S}$ o begin many Christmas parties in Australia, as guests break the ice by pulling Christmas crackers, playing with the prizes and donning the easyto-tear paper crowns found therein. While the groan-inducing jokes about frost, penguins and snowmen may seem out of place in the heat of summer, this tradition is as popular Down Under as in its native Britain. Traditionally, the person left holding the larger portion of the cracker is declared the winner of the prizes and gets to wear the paper crown during dinner. While the prizes are rarely anything to write home about (Box 1, Box 2), guests' competitive natures are aroused by the activity, and everyone would love to be a winner on their first try.

A natural follow-up to the pulling of crackers, particularly for parties where the guests are of a scientific bent, is to formulate theories on the best strategy to employ for a win. Such theories typically focus on technique and physical strength, but we consider here the possibility that attitude also plays a role. In contrast to the ambition typically found in those who aspire to be crowned king, in this study we investigate whether a "Bah, humbug!" passive-aggressive attitude towards Christmas may be of greater advantage. While such behaviour is typically seen as negative, ${ }^{1,2}$

Abstract

Objective: To test the effects of technique and attitude in pulling Christmas crackers.

Design, setting and participants: A binomial trial conducted at a Christmas-inJuly dinner party involving five anonymous dinner guests, including two of the authors.

Main outcome measure: Number of wins achieved by different strategies, with a win defined as securing the larger portion of the cracker.

Results: The previously "guaranteed" strategy for victory, employing a downwards angle towards the puller, failed to differentiate itself from random chance (win rate, 6/15; probability of winning, $0.40 ; 95 \% \mathrm{Cl}, 0.15-0.65$ ). A novel passive-aggressive strategy, in which one individual just holds on without pulling, provided a significant advantage (win rate, 11/12; probability of winning, $0.92 ; 95 \% \mathrm{Cl}, 0.76-1.00)$

Conclusion: The passive-aggressive strategy of failing to pull has a high rate of success at winning Christmas crackers; however, excessive adoption of this approach will result in a complete failure, with no winners at all.

it may be that the sports catchphrase "It's not whether you win or lose, it's how you play the game" paradoxically results in you winning far more often than losing.

\section{Methods}

\section{Technique or attitude?}

We first considered physiological features that might affect the application of stress (a commodity in ample supply at Christmas time). A cracker is made of a cardboard tube wrapped in colourful paper and resembles the shape of a giant sweet (Box 3). A standard cracker measures about $25 \mathrm{~cm}$ in length and has a fillable space of $10 \mathrm{~cm}^{3}$ to hold surprises: small gifts, jokes and paper crowns to make the partygoers look like Wise Men. The content can vary depending on the type of cracker. While the wrapper of smaller bonbons is

1 Summary of the winning content from the study, including barrettes, plastic rings, toy cars and red lips

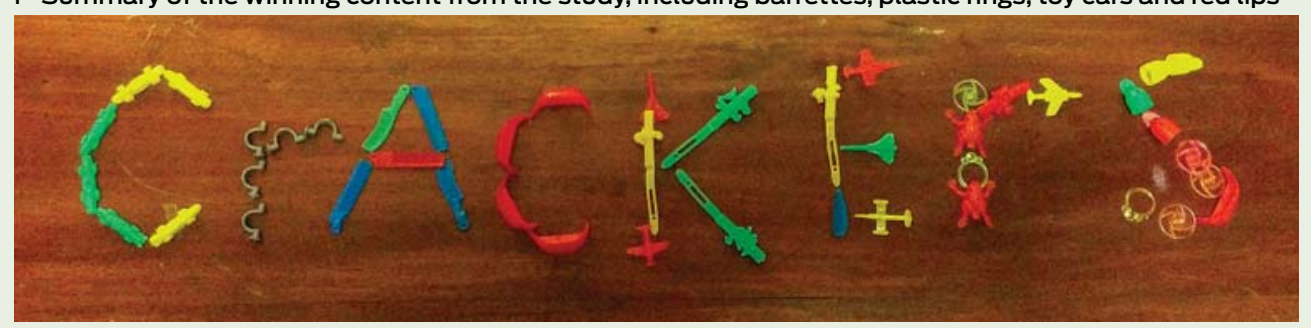

twisted to keep the filling inside, there is no twisting involved to seal crackers - instead the seams are perforated at the "twist" and tied off, practically guaranteeing that the cracker will break at one of these sites.

While many anecdotes on how to win at crackers have been traded over Christmas dinners, there has been very little controlled research on the subject. Researchers have previously identified factors influencing the chances of winning the content of a cracker, 3,4 including grip, angle, distance to the centre of gravity of the cracker, quality of the cracker, size of the cracker, pull and twist. Both these studies reported the importance of the angle at which the cracker is pulled down (optimally between $20^{\circ}$ and $55^{\circ}$ ), indicating this may be an important factor. ${ }^{3,4}$ One group of researchers even devised a formula, in which the optimal angle $=11 \times$ circumference $\div$ length $+5 \times$ quality of the cracker ( 1 for cheap, 2 for standard or 3 for premium). ${ }^{3}$

In this study, we focused on a single type of cracker and therefore ignored the factors relating to quality and size. We tested the following three strategies:

- The QinetiQ strategy: a firm twohanded grip, tilting the cracker 
2 Cracker jokes: the best of the worst

Question

What do you call a train loaded with toffee?

Why does Santa have three gardens?

What do you call a penguin in the Sahara desert?

Why did the tomato blush?

Where do snowmen go to dance?

\section{Cracker construction and use}

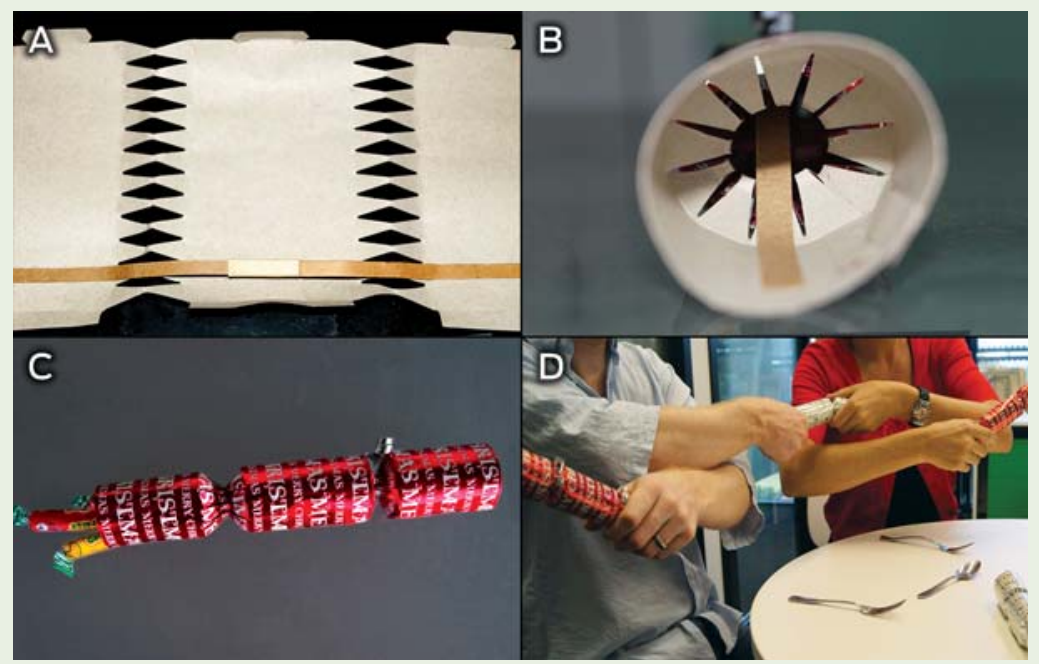

A cardboard wrapper with perforated seams has a noise strip glued to the interior $(\boldsymbol{A})$, is formed into a tube (B), filled with prizes and tied off at the perforations (C). Traditional crossed-arm pulling demonstrated by two anonymous participants (D).

between $20^{\circ}$ and $55^{\circ}$ downwards, and applying a steady force with no torque. ${ }^{4}$

- The passive-aggressive strategy: a firm two-handed grip at no angle, not pulling at all, and letting the other person do all the work.

- The control strategy: typical of Christmas parties around the world, where both participants pull at no particular angle but roughly parallel to the floor.

\section{Study design}

To determine whether any particular strategy had a greater than random chance of a win, we designed a binomial trial. We assumed that the probability of winning on each pull depended primarily on the strategy used, with some variability due to characteristics of the individual pullers. Five volunteers were recruited to pull crackers according to the different strategies, and for each cracker pull, the winner and details of the strategy were recorded. Volunteers

\section{Answer}

A chew chew train

So he can hoe hoe hoe

Lost

It saw the salad dressing

To a snowball

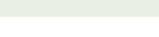


whether both participants pulled or only one pulled while the other just held on. The control strategy most closely replicated typical behaviour at Christmas parties and, as expected, was the strategy producing results closest to random (probability of a win, 0.53; 95\% CI, 0.28-0.79). The passive-aggressive strategy was the most successful strategy (probability of a win, $0.92 ; 95 \%$ CI, 0.76-1.00), where the individual who did not pull but merely held on firmly to the cracker won all but one time. This was the only strategy which could be declared "winning" in our study.

\section{Discussion}

During a Christmas-in-July party, we tested existing strategies and identified salient features of cracker pulling that may be used to be crowned king of the Christmas festivities. As the QinetiQ strategy had previously been described as "the perfect way to pull a Christmas cracker", 4 we had high expectations for its success. However, this was not supported by our investigations. In particular, in contrast to previous studies, we ruled out angle as a deciding factor in winning Christmas crackers. Further, we identified a novel passive-aggressive strategy as being the surest path to the crown.

Our study has some limitations. We attempted to account for seasonal trends by conducting our trial in winter. However, as Brisbane winters are substantially warmer than those in England (and, on occasion, English summers as well!), it is possible that our strategies would have different success rates in colder weather. We cannot claim that the passive-aggressive strategy is the only strategy
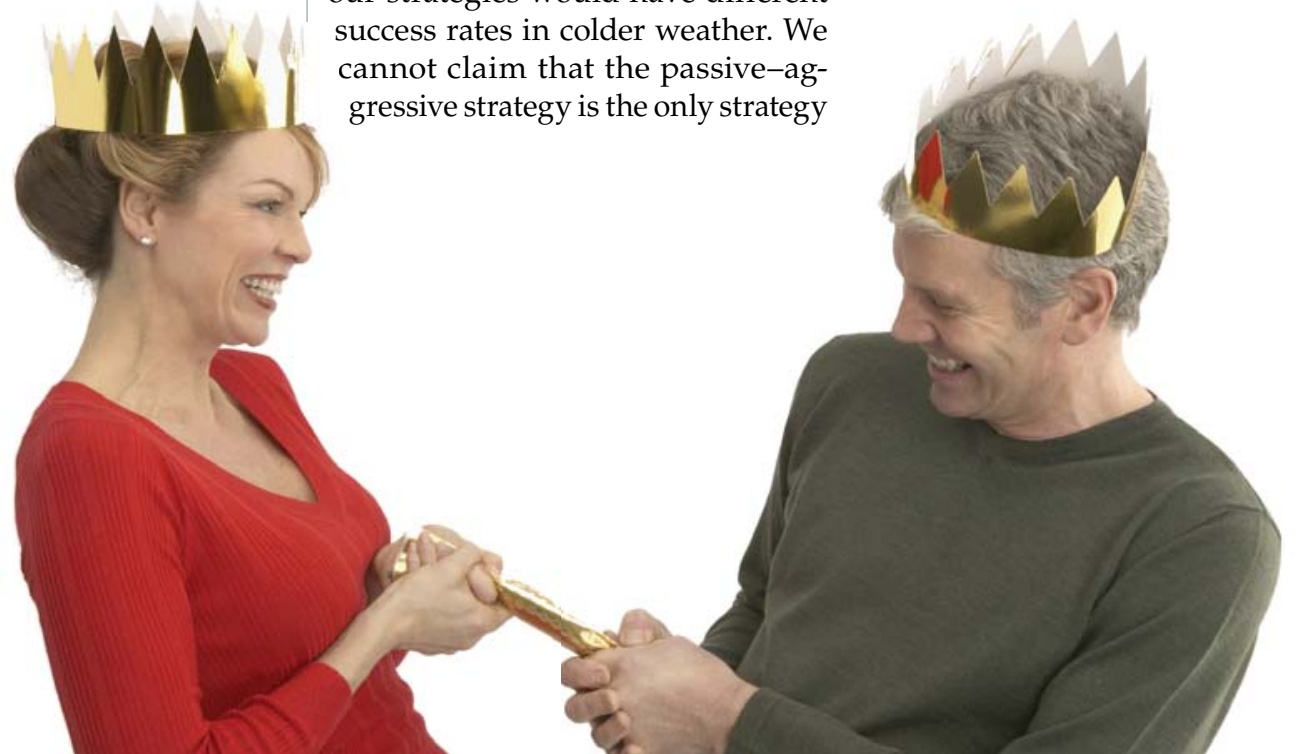

that will increase the chances of winning, as we did not have sufficient power to detect smaller deviations from random chance. However, it does seem that attitude may play a greater role than technique in achieving success with Christmas crackers. It is possible that this result is specific to the brand we used and will not generalise to all types of crackers. However, there is at least anecdotal evidence that this strategy has worked previously, ${ }^{5}$ although no evidence was given to support this claim.

Finally, we did not account for unintentional biases due to differences between volunteers - for example, one volunteer had never seen a cracker before in his life. This person's win rate was unusually high, with an average probability of winning of 0.71 (95\% CI, 0.52-0.91), significantly different from random chance. No other pullers had unusual prowess or lack thereof at pulling, so we must conclude that this person was influenced by the well documented phenomenon of beginner's luck. Interestingly, every time this individual pulled against someone employing the passive-aggressive strategy, he lost, in spite of his higher than normal success rate in general.

The traditional approach to cracker pulling sees all guests cross hands and pull crackers with their two neighbours (Box 3, D). With our final five crackers, we attempted to test whether our winning passiveaggressive strategy could be used to ensure success for all guests at once. Hence, all individuals pulled

we

for for a generous donation of Christmas crackers to the went home winners.

\section{Competing interests: No relevant disclosures.}

1 Dickens C. A Christmas carol: in prose, being a ghost story of Christmas. London: Chapman \& Hall, 1843.

2 Murphy T, Hoff Oberlin L. Overcoming passive-aggression: how to stop hidden anger from spoiling your relationships, career and happiness. New York: Marlowe \& Company, 2005.

3 Sims P. Formula that gives you the cracker knack. Daily Mail Australia 2009; Dec 24. http:// www.dailymail.co.uk/news/article-1238125/ Formula-gives-cracker-knack.html (accessed Sep 2014).

4 Snapping up a prize cracker. BBC News 2003; Dec 23. http://news.bbc.co.uk/2/hi/science/ nature/3342601.stm (accessed Sep 2014).

5 Christmas crackers warning... UK Fireworks Forum 2005; Dec 20. http://www.fireworksforum.org.uk/threads/christmas-crackerswarning.5343 (accessed Sep 2014).

6 McDonald D. The last gasp. CMAJ 2004; 171: 1571.

with their right hands, but not their left. Unfortunately, the strategy only achieved success for one person; two others won with both hands and the rest lost with both. While including these trials in our results did not alter we omitted them due to the differencsicular, only tho, was used for pulling each cracker, and as one of the individuals was left-handed, this may have influenced the success

The passive-aggressive strategy has important implications for future graphic, as it does not require great strength to implement. Indeed, the passivity of the approach may help to Second, the strategy is easy to employ with subtlety, unlike any strategy involving an angle, which must surely arouse suspicions in your pulling partner.

Finally, while the winning strategy does have a high success rate, this is true only if one member of the pair is aware of that fact. If both individuals employ the same strategy, the party could stretch on forever, resulting in a burnt dinner and both hosts and guests in tears. The moral of this is a caution against overindulgence in passive-aggressiveness - while judicious use may win you prizes, overdo it, and your goose will be cooked.

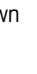

